\title{
History effect of light and temperature on monoterpenoid emissions from Fagus sylvatica L.
}

\author{
M. Demarcke ${ }^{a}$, J.-F. Müller ${ }^{a}$, N. Schoon ${ }^{a}$, H. Van Langenhove ${ }^{b}, J_{\text {. Dewulf }}^{b}$, E. Joó ${ }^{b}, K$. Steppe ${ }^{c}$, \\ M. Šimpraga ${ }^{c}$, B. Heinesch ${ }^{d}$, M. Aubinet ${ }^{d}$, C. Amelynck ${ }^{\mathrm{a}, *}$ \\ ${ }^{a}$ Belgian Institute for Space Aeronomy, Ringlaan 3, B-1180 Brussels, Belgium \\ ${ }^{\mathrm{b}}$ Research Group Environmental Organic Chemistry and Technology, Faculty of Bioscience Engineering, Ghent University, Ghent, Belgium \\ ${ }^{\mathrm{c}}$ Laboratory of Plant Ecology, Faculty of Bioscience Engineering, Ghent University, Ghent, Belgium \\ ${ }^{\mathrm{d}}$ Unité de Physique des Biosystèmes, Gembloux Agro-Bio Tech, Université de Liège, Gembloux, Belgium
}

\section{A R T I C L E I N F O}

\section{Article history:}

Received 8 April 2010

Received in revised form

27 May 2010

Accepted 28 May 2010

\section{Keywords:}

Monoterpene

Monoterpenoid

Fagus sylvatica L.

Emission algorithm

MEGAN

PTR-MS

\begin{abstract}
A B S T R A C T
Monoterpenoid emissions from Fagus sylvatica L. trees have been measured at light- and temperaturecontrolled conditions in a growth chamber, using Proton Transfer Reaction Mass Spectrometry (PTR-MS) and the dynamic branch enclosure technique.

De novo synthesized monoterpenoid Standard Emission Factors, obtained by applying the G97 algorithm (Guenther, 1997), varied between 2 and $32 \mu \mathrm{g} \mathrm{g} \mathrm{DWW}^{-1} \mathrm{~h}^{-1}$ and showed a strong decline in late August and September, probably due to senescence.

The response of monoterpenoid emissions to temperature variations at a constant daily light pattern could be well reproduced with a modified version of the MEGAN algorithm (Guenther et al., 2006), with a typical dependence on the average temperature over the past five days.

The diurnal emissions at constant temperature showed a typical hysteretic behaviour, which could also be adequately described with the modified MEGAN algorithm by taking into account a dependence on the average light levels experienced by the trees during the past $10-13 \mathrm{~h}$.

The impact of the past light and temperature conditions on the monoterpenoid emissions from F. sylvatica L. was found to be much stronger than assumed in previous algorithms.

Since our experiments were conducted under low light intensity, future studies should aim at confirming and completing the proposed algorithm updates in sunny conditions and natural environments.
\end{abstract} (C) 2010 Elsevier Ltd. All rights reserved.

\section{Introduction}

Vegetation plays an important role in earth-atmosphere interactions due to its importance for the carbon cycle but also as a source of a variety of reactive volatile organic compounds. The global annual flux of non methane volatile organic compounds (NMVOC) emitted from vegetation is estimated to be $1150 \mathrm{Tg} \mathrm{C}^{-1}$ (Guenther et al., 1995). With respective estimates between 454 and $601 \mathrm{Tg} \mathrm{C} \mathrm{y}{ }^{-1}$ and between 32 and $127 \mathrm{Tg} \mathrm{C} \mathrm{y}^{-1}$, isoprene and monoterpenes represent a large part of the NMVOC flux (Arneth et al., 2008). The large variability of these estimates, especially for monoterpenes, reflects a lack of observations for constraining the emission models. Whereas on a global scale monoterpene emission rates are only $\sim 15 \%$ of isoprene emission rates, a recent NMVOC

\footnotetext{
* Corresponding author. Tel.: +32 237303 90; fax: +32 23748423.

E-mail address: crist.amelynck@aeronomie.be (C. Amelynck).
}

inventory predicts equal isoprene and monoterpene emission rates in Europe (Karl et al., 2009), showing the relative importance of the latter species in Europe.

Accurate estimates of these emissions are needed, because atmospheric oxidation of these compounds has an important impact on the budget of oxidants, in particular ozone $\left(\mathrm{O}_{3}\right)$ and the hydroxyl radical $(\mathrm{OH})$ (Seinfeld and Pandis, 1998). Furthermore, isoprenoids represent a large source of Secondary Organic Aerosol (SOA) due to the gas-to-particle conversion of low-volatility oxidation products (Kulmala et al., 2004), and the large variability on global monoterpene emission rates results in very high uncertainties on bottom-up estimates of global biogenic SOA fluxes (Hallquist et al., 2009).

Many plant species (e.g. most conifers) store monoterpenes in special storage tissues or organs and the diffusion of monoterpenes out of these structures is driven by temperature (Kesselmeier and Staudt, 1999). However, several plant species, which lack these storage compartments, are known to emit de novo biosynthesized 
monoterpenes. These emissions are driven by light and temperature in a similar way as for isoprene emissions (Staudt and Seufert, 1995). Moreover, they appear also to depend on light and temperature levels experienced by the plant in the previous hours, days or even weeks. The dependence on temperature during previous days or weeks has been observed in the case of isoprene (Monson et al., 1994; Sharkey et al., 1999; Pétron et al., 2001; Rapparini et al., 2004) and 2-methyl-3-buten-2-ol (MBO) (Gray et al., 2003, 2006). This dependence is apparently due to changes in the concentration of enzymes responsible for the production of these compounds (Schnitzler et al., 1997) and is consistent with their hypothesized role as thermal protectant (Sharkey et al., 2008). Since nonoxygenated monoterpenes might contribute to heat stress resistance (Copolovici et al., 2005), temperature history effects as observed for isoprene can be expected for monoterpenes as well. Indeed, dependence on past temperature and light levels has been reported for (de novo synthesized) monoterpene emissions from Quercus ilex L. (Staudt et al., 2003). The acclimatization time was observed to vary from a few days to several weeks, and downregulation of the emission capacity was found to be slower than upregulation. In addition, monoterpene emissions are expected to depend on past environmental conditions during the previous minutes or hours, due to the existence of transient storage pools, as suggested for instance by the observed temporal dynamics of ${ }^{13} \mathrm{C}$ incorporation into newly synthesized monoterpenoid emissions (Noe et al., 2006, 2010). The time-lag between monoterpene production and emission is compound-specific and depends on the Henry's law constant and the octanol/water partitioning coefficient.

Dependence of emissions on past radiation levels is suggested from the observed hysteretic behaviour of monoterpene emissions from Fagus sylvatica L. reported by Dindorf et al. (2005) in natural environmental conditions, with higher emissions in the afternoon than in the morning at constant light and temperature levels. Note that dependence on past radiation levels could be (at least partly) due to leaf heating (Gray et al., 2006).

The history effects observed for isoprene emissions have been parameterized in the algorithm of Guenther et al. (1999, 2006). However, the shape of the response curve to past weather conditions is highly uncertain, despite its demonstrated importance in the simulation of seasonal variations of isoprene emissions. Furthermore, its applicability to the emissions of other NMVOCs is questionable.

Due to the strong co-variation of temperature and light in natural conditions, it is often difficult to separate the effects of both parameters on BVOC emissions. Therefore the present study focuses on the light and temperature dependence of monoterpene emissions by $F$. sylvatica L., a common European tree species, measured under controlled light and temperature conditions in a growth chamber.

\section{Experimental set-up and methods}

Experiments were carried out successively on two three-year old beech (F. sylvatica L.) trees. Both trees were grown in outdoor conditions and were allowed to acclimate to the growth chamber conditions for at least one month prior to the start of the measurements. VOC emissions were obtained by putting a single branch of each tree in a dynamic enclosure system and continuously monitoring the emitted species with a Proton Transfer Reaction Mass Spectrometer (PTR-MS). These continuous measurements were occasionally complemented by enclosure air sampling, followed by off-line analysis by Thermal Desorption Gas Chromatography Mass Spectrometry (TD-GC-MS) for VOC speciation.

\subsection{Controlled environment}

In the growth chamber $(2 \times 1.5 \times 2 \mathrm{~m}$; height $\times$ width $\times$ length $)$ the trees were subjected to a controlled light and temperature regime. The daily light pattern was simulated by varying the light intensity in eight steps by means of a set of 40 fluorescent lamps (type PHILIPS Master TL-D fluorescent lamps 36W/830 warm white, super 80). The maximum photosynthetic photon flux density (PPFD) that was obtained at branch level was $150 \mu \mathrm{mol} \mathrm{m}{ }^{-2} \mathrm{~s}^{-1}$. The incident PPFD was monitored by a quantum sensor (LI-190SA, LI-COR, USA), positioned next to the branch enclosures at the same height of the leaves of the enclosed branch. The daily PPFD pattern imposed on the enclosed branch of the second tree is shown in the upper graph of Fig. 2 and is similar to the one imposed on the enclosed branch of the first tree.

For the second tree, a horizontal Teflonated grid was used to gently flatten the leaves and to avoid leaf overlap with the aim to ensure a homogeneous light distribution over the leaves enclosed. The total leaf area and total leaf dry weight were $0.181 \mathrm{~m}^{2}$ and $0.89 \mathrm{~g}$ for the enclosed branch of the first tree and $0.0120 \mathrm{~m}^{2}$ and $0.59 \mathrm{~g}$ for the enclosed branch of the second tree.

The temperature in the growth chamber was controlled by means of an air conditioning system. During the experiments with the first tree, daily averaged leaf temperatures of the enclosed branch were 21 (13-16/07), 19.5 (17-18/07) and $18{ }^{\circ} \mathrm{C}(20-22 / 07)$. Measurements taken during temperature transition periods were excluded from the analysis. During the experiments with the second tree, the leaf temperature for the enclosed branch varied between 17 and $27{ }^{\circ} \mathrm{C}$, as shown in Fig. 3 (upper graph). The air temperature outside and inside the enclosures was monitored by thermistors (type 10k, NTC, Omega, NL). Leaf temperature was measured by an infrared thermocouple (type IRt/c.1X, Exergen, MA USA), mounted in a Teflon housing and installed in the cuvette about $5 \mathrm{~mm}$ under the surface of a single beech leaf. Relative humidity sensors were installed in the outlet line of each cuvette (type HIH-3610, Honeywell, NJ, USA) and in the growth chamber itself (type RHa, Rotronic, $\mathrm{CH}$ ).

\subsection{Branch enclosure system and incoming air supply system}

The dynamic branch enclosure system consists of a transparent cylindrical box with a volume of $12.2 \mathrm{~L}$ and is shown in



Fig. 1. Dynamic enclosure system containing a branch of a Fagus sylvatica L. tree (second tree) 

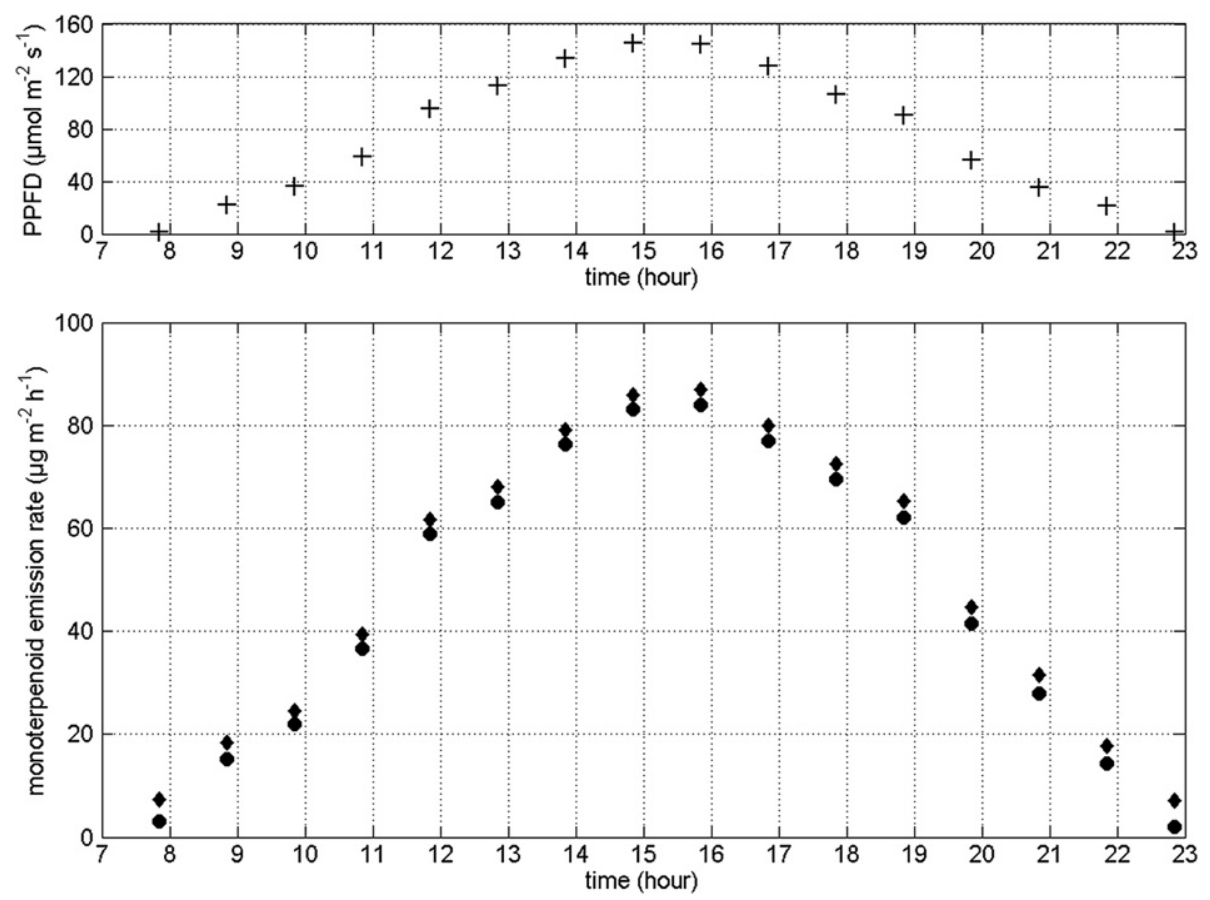

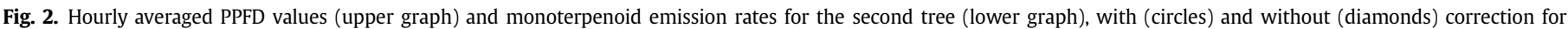
nighttime emissions. The values represent averages over the entire experimental period.

Fig. 1. The external frame is made of a transparent polymethylmethacrylate (PMMA) base plate, three PMMA rings and three aluminum bars, which hold a cylindrical $50 \mu \mathrm{m}$ thick perfluoroalkoxy Teflon (PFA) envelope (Norton, Saint-Gobain Performance Plastics, NJ, USA) with a solar transmission of $96 \%$. The base plate contains two PFA gas feedthroughs (bulkheads) for incoming and exiting air, as well as a Teflon feedthrough for electrical connections inside the cuvette. The emitted biogenic volatile organic compounds (BVOCs) and the incoming air are efficiently homogenized by means of a Teflon ventilator, which is
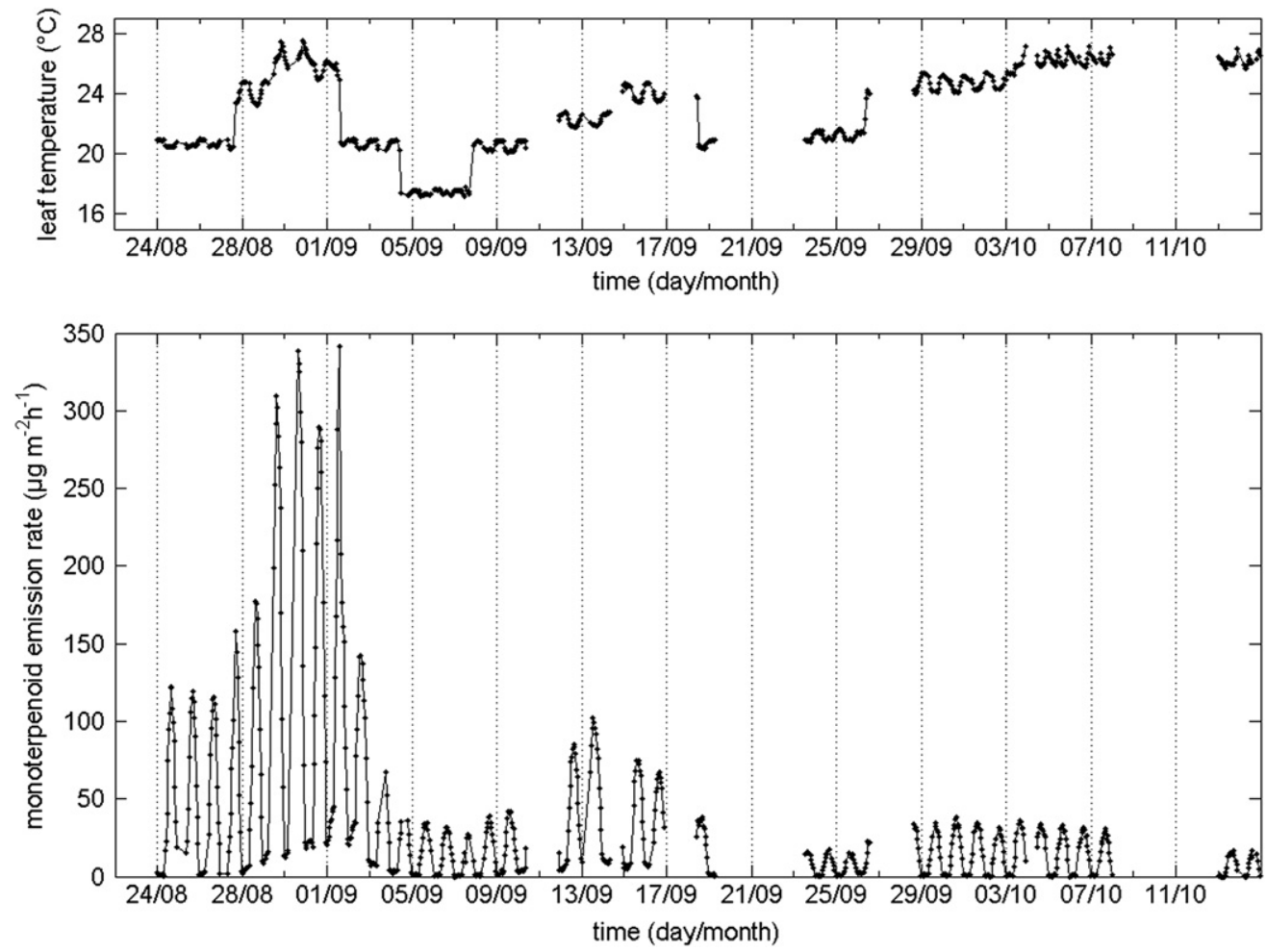

Fig. 3. Temporal evolution of leaf temperature and monoterpenoid emission rates $\left(\mu \mathrm{g} \mathrm{m}^{-2} \mathrm{~h}^{-1}\right)$ for the enclosed branch of the second beech tree. 
mounted on the base plate. The air exit opening of the cuvette is sufficiently large to avoid overpressure in the cuvette. While enclosing the branch in the cuvette, extreme care was taken not to bend the branch too much and not to injure any leaves, in order to avoid unwanted stress-induced BVOC emissions.

Ambient air from above the roof of the building was pumped by a diaphragm pump (MD4, Pfeiffer Vacuum, Germany) and purified by a dust filter ( $2 \mu \mathrm{m}$ pore size Zefluor ${ }^{\mathrm{TM}}$ PTFE Membrane Filter, Pall, MI, USA) and an ozone filter, consisting of a set of $12 \mathrm{MnO}_{2}$-coated copper nets (type ETO341FC004, Ansyco, Germany) housed in an aluminum filter holder. The air was subsequently sent through a set of two active coal filters (Airpel 10, Organosorb 10-CO, Desotec, Belgium), the combination of which resulted in an optimal pore size distribution for absorption of VOCs. To prevent carry-over of carbon powder a second dust filter was placed downstream the active coal filters. The purified air was then distributed to three flow meters (5860S (0-30 L min ${ }^{-1}$ ), BROOKS Instrument, PA, USA), all followed by manual ball valves (type SS-43S4, Swagelok, OH, USA). By adjusting the valve settings, all cuvettes were provided with identical dust-, $\mathrm{O}_{3}$ - and VOC-free air flows of typically $5 \mathrm{~L} \mathrm{~min}^{-1}$ (at standard conditions of pressure (1013.25 hPa) and temperature $(293 \mathrm{~K})$ ). Ozone levels in the incoming air were regularly checked at the cuvette inlet with an ECC Ozonesonde (EN-SCI, Inc., Boulder, USA) and were found to be below 2 ppbv at all times.

Part of the BVOC-enriched air flow exiting each of the cuvettes was continuously pumped through PFA tubes towards a PFA gas multiplexer. The rest of the outgoing cuvette air was sent into the growth chamber.

\subsection{BVOC analysis}

A small part (about $20 \mathrm{~mL} \mathrm{~min}^{-1}$ ) of the $1 \mathrm{~L} \mathrm{~min}^{-1}$ BVOCenriched air flow which was sampled from the cuvettes was introduced in a high sensitivity Proton Transfer Reaction Mass Spectrometer (hs-PTR-MS, Ionicon Analytik GmbH, Austria). This sensitive and fast on-line VOC analyzer is based on the soft chemical ionization of analyte molecules by proton transfer reactions with hydronium $\left(\mathrm{H}_{3} \mathrm{O}^{+}\right)$ions. Detailed information on the technique can be found in a number of extensive review articles (de Gouw and Warneke, 2007; Blake et al., 2009). In the present experiments, the PTR-MS was operated at a drift tube pressure of $2.2 \mathrm{mbar}$ and an $E / N$ value of $140 \mathrm{Td}\left(1 \mathrm{Td}=10^{-17} \mathrm{~V} \mathrm{~cm}{ }^{2}\right)$. The temperature of the capillary inlet line and the drift tube reactor were kept at $333 \mathrm{~K}$.

The PTR-MS ion signal at $m / z 137$ (protonated monoterpene, $\mathrm{C}_{10} \mathrm{H}_{17}^{+}$) was used to monitor the sum of monoterpenes. Monoterpene calibration was performed regularly by using a gravimetrically prepared mixture of $\alpha$-pinene $(0.47 \mathrm{ppmv})$ and sabinene (0.41 ppmv) in nitrogen (Apel-Riemer Inc., Denver, CO, USA), with a certified accuracy of $5 \%$.

Cuvette air samples were taken occasionally and analyzed offline by TD-GC-MS (Joó et al., 2010) to determine the monoterpene emission pattern. These analyses revealed the presence of linalool which also contributes to the ion signal at $\mathrm{m} / \mathrm{z} 137$ and therefore interferes with monoterpene detection. Consequently, the BVOC emissions that were inferred from the PTR-MS ion signal at $m / z 137$ included both monoterpenes and linalool and will be called monoterpenoid emissions hereafter. A fraction of the ion signal at $\mathrm{m} / \mathrm{z}$ 137 can also be due to the emission of $\alpha$-farnesene, a sesquiterpene which was also observed by TD-GC-MS (Joó et al., 2010). However, this fraction was estimated to be at most 3-5\% and was therefore neglected in the further analysis.

The procedure to determine accurate monoterpenoid emission rates, taking into account the experimentally determined monoterpene calibration factor, the ratio of the detection sensitivity of monoterpenes (mainly sabinene) to the one of linalool at $m / z 137$, as well as the fractional contribution of both species to the sum of monoterpenoids (as determined by TD-GC-MS), has been described in detail in by Joó et al. (2010).

\subsection{Emission algorithms}

Monoterpene emissions by F. sylvatica L. are known to be temperature and light dependent. Since, however, small nighttime emissions have been observed, probably due to a temperaturedependent release from non-specific storage pools (Schuh et al., 1997 ), we write the emission ( $E$ in $\mu \mathrm{g} \mathrm{m}^{-2} \mathrm{~h}^{-1}$ ) of monoterpenoids by F. sylvatica L. as

$E=E_{n s}+E_{p}$

where $E_{n s}$ is the newly synthesized emission component and $E_{p}$ represents the release from storage pools. The light and temperature-dependent part, $E_{n s}$, has been often described by the emission algorithm of Guenther (1997) originally developed for isoprene:

$E_{n s, G 97}=\varepsilon_{G 97} \cdot \gamma_{T, G 97} \cdot \gamma_{P, G 97}$

where $\varepsilon_{\mathrm{G} 97}\left[\mu \mathrm{g} \mathrm{m} \mathrm{m}^{-2} \mathrm{~h}^{-1}\right]$ is a standard emission factor (SEF), i.e. the emission rate at standardized conditions $\left(30^{\circ} \mathrm{C}, 1000 \mu \mathrm{mol} \mathrm{m}^{-2} \mathrm{~s}^{-1}\right)$, typical for the tree considered; $\gamma_{T, G 97}$ and $\gamma_{P, G 97}$ describe the dependence of the emissions on temperature and photosynthetically active radiation, respectively. In the formulation of Guenther (1997), $\varepsilon_{G 97}$ is constant; however, the SEF for Fagus sylvatica L. is known to show a significant decrease between spring and autumn probably associated with the phenological development (i.e. the age) of the leaves (Schuh et al., 1997; König et al., 1995). We adopt therefore the more general expression:

$E_{n s}=\varepsilon \cdot \gamma_{\text {age }} \cdot \gamma_{T} \cdot \gamma_{P}$

where $\gamma_{\text {age }}$ accounts for these variations due to phenology. Several choices are possible for the response functions $\gamma_{T}$ and $\gamma_{P}$ : (1) Guenther (1997) (G97), (2) Schuh et al. (1997) (S97), (3) Guenther et al. (2006) (G06), (4) Gray et al. (2006) (Gray), and (5) a modified form of the G06 algorithm (G06a), with parameters fitted using the measurements presented in the next Section.

The G97 and G06 models were originally developed for isoprene emissions using experimental emission rate data from several tree species; the S97 algorithm was developed using sunflower as a model plant and beech to confirm its applicability for other plant species; the Gray algorithm was developed to parameterize the impact of both instantaneous and past temperatures for methylbutenol (MBO) emissions from needles of ponderosa pine trees.

The response function $\gamma_{T}$ in the G97 algorithm (Guenther, 1997) is given by:

$\gamma_{T, G 97}=\frac{\exp \left(\frac{C_{T 1} \cdot\left(T-T_{S}\right)}{R \cdot T \cdot T_{S}}\right)}{C_{T 3}+\exp \left(\frac{C_{T 2} \cdot\left(T-T_{M}\right)}{R \cdot T \cdot T_{S}}\right)}$

$C_{T 1}=95000 \mathrm{~J} \mathrm{~mol}^{-1}, C_{T 2}=230000 \mathrm{~J} \mathrm{~mol}^{-1}$ and $C_{T 3}=0.961$ are empirical coefficients, $R=8.314 \mathrm{~J} \mathrm{~K}^{-1} \mathrm{~mol}^{-1}$ is the universal gas constant, $T$ is leaf temperature $[\mathrm{K}], T_{M}=314 \mathrm{~K}$, and $T_{S}=303 \mathrm{~K}$. The corresponding light response function is given by:

$\gamma_{P, G 97}=C_{L, G 97} \cdot \frac{\alpha_{G 97} \cdot L}{\sqrt{1+\alpha_{G 97}^{2} \cdot L^{2}}}$

where $L$ is the photosynthetic photon flux density (PPFD) in $\mu \mathrm{mol} \mathrm{m} \mathrm{m}^{-2} \mathrm{~s}^{-1}$, whereas $\alpha_{\mathrm{G} 97}=0.0027$ and $C_{L, \mathrm{G} 97}=1.066$ are empirical coefficients. 
Whereas the temperature dependence of the emissions according to Schuh et al. (1997) is very similar to the response function $\gamma_{T, G 97}$, the light dependence of the S97 algorithm is a sigmoidal curve expressed as:

$\gamma_{P, S 97}=C_{L, S 97} \cdot\left(\frac{\alpha_{S 97} \cdot L}{\sqrt{1+\alpha_{S 97}^{2} \cdot L^{2}}}\right)^{2}$

where $\alpha_{\mathrm{S} 97}$ and $\mathrm{C}_{\mathrm{L}, \mathrm{S} 97}$ are equal to $\alpha_{\mathrm{G} 97}$ and $\mathrm{C}_{\mathrm{L}, \mathrm{G} 97}$, respectively.

The temperature response function in Gray et al. (2006) which achieves the best agreement with their MBO flux measurements involves a correction factor to the G97 algorithm:

$\gamma_{T, \text { Gray }}=\gamma_{T, G 97} \cdot\left(0.822 \cdot \frac{T-T_{0}}{30}+0.805 \cdot \frac{T_{7 d}-T_{0}}{30}-0.601\right)$

where $T_{0}=273 \mathrm{~K}$ and $T_{7 d}$ is the average daily maximum temperature for the previous 7 days.

The isoprene emission algorithm in MEGAN (Model of Emissions of Gases and Aerosols from Nature) (Guenther et al., 2006) incorporates a dependence of the emissions on leaf age and soil moisture, as well as updated temperature and light response functions accounting for the observed role of past meteorological conditions. Both MEGAN (G06) and a generalized form of the MEGAN algorithm (G06a) will be tested against our measurements. The temperature response function of G06 is:

$\gamma_{T, G 06}=E_{o p t, G 06} \cdot\left(\frac{C_{T 2} \cdot \exp \left(C_{T 1} \cdot x\right)}{C_{T 2}-C_{T 1} \cdot\left(1-\exp \left(C_{T 2} \cdot x\right)\right)}\right)$

with

$x=\frac{\left(T_{\text {opt }, G 06}^{-1}-T^{-1}\right)}{R}$

where $R, C_{T 1}$ and $C_{T 2}$ are as in Eq. (4); $E_{\text {opt,G06a }}$ is the maximum normalized emission capacity, and $T_{o p t, G 06 a}$ is the temperature at which $E_{o p t, \mathrm{G} 06 \mathrm{a}}$ occurs. These quantities depend on the average leaf temperature over the past $24 \mathrm{~h}\left(T_{24} \mathrm{~h}\right)$ and the past $m$ days $\left(T_{m d}\right)$ and are given by:

$T_{\text {opt }, \text { G06a }}=313+0.6 \cdot\left(T_{m d}-297\right)$

$E_{\text {opt }, G 06 a}=2.038 \cdot \exp \left(\alpha_{1} \cdot\left(T_{24 h}-297\right)+\alpha_{2} \cdot\left(T_{m d}-297\right)\right)$

where $m, \alpha_{1}$ and $\alpha_{2}$ are adjustable parameters (note that $m=10$, $\alpha_{1}=\alpha_{2}=0.05$ in MEGAN).

The light response function in G06a is expressed as:

$\gamma_{P, G 06 a}=C_{L, G 06 a} \cdot \frac{\alpha_{G 06 a} \cdot L}{\sqrt{1+\alpha_{G 06 a}^{2} \cdot L^{2}}}$

with

$\alpha_{G 06 a}=\alpha_{3} \cdot\left(0.004-0.0005 \cdot \ln \left(P_{10 d}\right)\right)$

$C_{L, G 06 a}=0.0468 \cdot \exp \left(\alpha_{4} \cdot\left(P_{n h}-P_{0}\right)\right) \cdot P_{10 d}^{0.6}$

where $P_{n h}$ and $P_{10 \mathrm{~d}}\left[\mu \mathrm{mol} \mathrm{m} \mathrm{m}^{-2} \mathrm{~s}^{-1}\right.$ ] are the PPFD averages over the last $n$ hours and 10 days, respectively, $P_{0}$ is equal to $200 \mu \mathrm{mol} \mathrm{m}^{-2} \mathrm{~s}^{-1}$ for sunlit leaves and $50 \mu \mathrm{mol} \mathrm{m}^{-2} \mathrm{~s}^{-1}$ for shaded leaves, respectively. $\alpha_{3}$ and $\alpha_{4}$ are adjustable parameters $(n=24$, $\alpha_{3}=1$ and $\alpha_{4}=0.0005$ in MEGAN). Due to the constant diurnal
PPFD pattern in our experiments, $P_{10 d}$ and $P_{24} \mathrm{~h}$ are constant and both equal to $50 \mu \mathrm{mol} \mathrm{m} \mathrm{m}^{-2} \mathrm{~h}^{-1}$.

\section{Results and discussion}

The first part of this section deals with small nighttime ion signals that were observed at $m / z 137$, and how these were accounted for in the derivation of standard emission factors for the newly synthesized monoterpenoids. Subsequently, the performance of the different emission algorithms in describing the experimental results will be assessed and the effect of previous temperature and light conditions on the emissions will be quantified.

\subsection{Nighttime emissions and standard emission factors}

The temporal evolution of the monoterpenoid emission rate from a branch of the second F. sylvatica L. tree is shown in Fig. 3, along with the variation in leaf temperature, from August 24th until October 15th.

Gaps in the data are mainly due to instrumental problems and power failures. Monoterpenoid emissions clearly followed the daily imposed PPFD profile (Fig. 2) and responded to a large extent to leaf temperature variations. However, in late September and early October this reponse was masked by a general decline of the emissions, which was observed over the entire period and which is discussed in more detail in Section 3.2 .

This light and temperature dependence of monoterpene emissions by F. sylvatica L., with emissions close to zero at darkness, is in agreement with what has been reported previously by several authors (Schuh et al., 1997; Spirig et al., 2005; Holzke et al., 2006; Moukhtar et al., 2005; Dindorf et al., 2006). In the beginning and at the end of the experimental period the emission rate at zero PPFD was found to be negligible. Between August 28th and September 4th and between September 9th and September 18th, small PTR-MS ion signals at $m / z 137$ appeared in dark conditions, amounting to at most $12 \%$ of the maximum daytime emission rate, with the exception of one day at which a value of $20 \%$ was reached (September 2nd). Schuh et al. (1997) previously reported small emissions of $\alpha$-pinene at zero light flux in growth chamber experiments on F. sylvatica L., indicating the presence of non-specific storage pools. The monoterpenoid emission pattern in our experiments, however, contained no $\alpha$-pinene but was mainly composed of sabinene, linalool, ocimene and an unidentified monoterpene, as determined by GC-MS analysis of sampled air from the branch enclosure (Joó et al., 2010). Sabinene was the predominant $\mathrm{C}_{10} \mathrm{H}_{16}$ compound and linalool was always present in non-negligible amounts.

Although the nighttime emission rates calculated from the PTR-MS ion signal at $m / z 137$ are considered to be monoterpenoid emission rates, it cannot be excluded that other BVOCs (e.g. sesquiterpenes for which temperature-dependent dark emissions can be expected) also contributed to this ion signal to some extent.

In order to separate this limited light independent contribution from the major light dependent contribution to the monoterpenoid emission rates, linearly interpolated dark emission rates were subtracted from the hourly averaged daytime emission rates. Emission rates obtained at 11 PM of the day of the measurement and $11 \mathrm{PM}$ of the previous day were used for this interpolation. The influence of this correction on the hourly averaged emissions over the entire experimental period is shown in Fig. 2. In the following discussion, the corrected, daytime emission data are compared with literature data and tested against existing emission algorithms for newly synthesized monoterpenoids. 
The values of the daily standard emission factors $\left(\varepsilon_{G 97}\right.$, see Eq. (2)) inferred from the measured monoterpenoid emission rates of the second tree are found to vary between 100 and $1550 \mu \mathrm{g} \mathrm{m}^{-2} \mathrm{~h}^{-1}$ or 2 and $32 \mu \mathrm{gg}_{\mathrm{DW}}^{-1} \mathrm{~h}^{-1}$, in good agreement with literature data reported for F. sylvatica L. in recent years (Schuh et al., 1997; Kahl et al., 1999; Spirig et al., 2005; Moukhtar et al., 2005; Dindorf et al., 2006), which have been recently compiled in Table 3 of Dindorf et al. (2006), and with the values adopted in the two most recent European plant-specific BVOC inventories, $22.1 \mu \mathrm{g} \mathrm{g}_{\text {DW }}^{-1} \mathrm{~h}^{-1}$ (Karl et al., 2009) and $10.0 \mu \mathrm{g} \mathrm{g}_{\text {DW }}^{-1} \mathrm{~h}^{-1}$ (Schurgers et al., 2009).

\subsection{Response of monoterpene emissions to temperature variations at constant daily PPFD pattern}

The temporal variation of the standard emission factors $\varepsilon_{\mathrm{G} 97}$ for the second tree is shown in Fig. 4.

The SEFs are normalized by their value on August 24 $\left(1020 \mu \mathrm{g} \mathrm{m}^{-2} \mathrm{~h}^{-1}\right)$. Two features are prominent: a general decrease of the SEF during the course of the experimental period, very probably related to senescence, and a large peak around September 1 st. The effect of senescence is crudely parameterized by an exponential decrease of the leaf age activity factor (Eq. (3)) with time:

$\gamma_{\text {age }}=\exp \left(-\left(t-t_{0}\right)\right) / t_{s}$

where $t_{\mathrm{s}}$ (=18 days) is a characteristic time for the effect of senescence, fitted from the measurements, and $t_{0}$ is August 24th. As seen in Fig. 4, $\gamma_{\text {age }}$ decreased by almost an order of magnitude in less than 6 weeks. Although such a fast decline might be partly due to the unusual environment of the growth chamber, it is qualitatively consistent with the seasonal decline of the SEFs reported e.g. by Schuh et al. (1997).

The maximum SEF on September 1 st $(\sim 50 \%$ above the initial SEF on August 24th) occurred at the end of a 5-day period with warmer temperatures (up to $26^{\circ} \mathrm{C}$, see Fig. 2). Taking the effect of senescence (i.e. $\gamma_{\text {age }}$ ) into account, the emission capacity approximately doubled in response to the $5{ }^{\circ} \mathrm{C}$ warming imposed on the tree in this period. In the following days, the decrease in temperature was immediately followed by an abrupt decrease in SEF amounting to a factor of 5 in only one week. The dependence of SEF on temperature history suggested by this pattern is much stronger

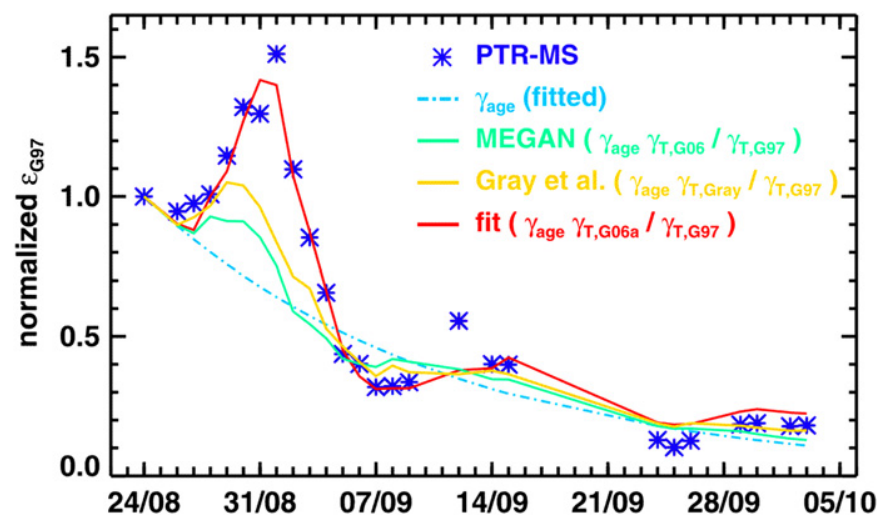

Fig. 4. Daily standard emission factor $\varepsilon_{\mathrm{G} 97}$ derived from the measurements with the second tree, and normalized by its value on 24/08 (stars), and comparison with modeled values based on three algorithms for the temperature response: MEGAN (green), Gray et al. (yellow) and the adjusted algorithm G06a (red). The assumed senescence factor $\left(\gamma_{\text {age }}\right)$ used in the calculations and inferred from the data is also shown. than in existing emission algorithms accounting for temperature history effects, such as MEGAN and the algorithm developed by Gray et al. (2006) (green and yellow curves on Fig. 4). It is, however, similar in magnitude to the acclimation of isoprene emission capacity by Quercus macrocarpa to changes in growth temperature observed by Pétron et al. (2001): a $5{ }^{\circ} \mathrm{C}$ warming was found to double the emission capacity of $Q$. macrocarpa, while a subsequent cooling led to a strong reduction in SEF, by a factor up to 4 on a time scale of several days. The monoterpene emission capacity of $Q$. ilex has been observed by Staudt et al. (2003) to respond even more drastically to the temperature regime: in so-called shaded conditions (PPFD $\leq 300 \mu \mathrm{mol} \mathrm{m}^{-2} \mathrm{~s}^{-1}$ ), the emission capacity increased by almost an order of magnitude in less than one week when the growth temperature was increased by $10^{\circ} \mathrm{C}$.

The observed temporal evolution of the daily SEF values was used to constrain the temperature dependence of the algorithm G06a, by minimizing the root mean square deviation between modeled and observed daily SEFs. The best match was found when including a strong dependence on the average temperature over the last 5 days ( $m=5$ ), with $\alpha_{2}=0.21$ in Eq. (11). Dependence on the average temperature over the last day was weak $\left(\alpha_{1}=0.03\right)$.

The temporal evolution of the SEF for the first tree (Fig. 5) provides some confirmation of the parameterized influence of past temperature on the emissions.

The reasons for the small increase during the first days (before 16/07) are unclear, since temperature remained constant during that period. Afterwards, the SEF steadily declined in response to a decrease in temperature, in agreement with the G06a algorithm constrained by data from the second tree, and in reasonable agreement with the algorithm of Gray et al. (2006). The effect of senescence was assumed to be unimportant during that period.

\subsection{Response of monoterpenoid emissions to PPFD variations at fixed temperatures}

Fig. 6 illustrates the response of monoterpenoid emissions to PPFD during selected days for the second tree. Temperature was constant during each series of days $\left(21^{\circ} \mathrm{C}\right.$ on $24-26 / 08,18{ }^{\circ} \mathrm{C}$ on $5-6 / 09,24^{\circ} \mathrm{C}$ on $30 / 09-01 / 10$ ).

The emissions were found to be consistently and significantly lower in the morning compared to the afternoon at the same PPFD level, which resulted in a genuine hysteretic behaviour. Note that



Fig. 5. Standard emission factor $\varepsilon_{\mathrm{G} 97}$ derived from the measurements with the first tree, and normalized by its value on 13/07 (stars), and comparison with modeled values based on MEGAN (green), Gray et al. (yellow) and the algorithm G06a adjusted using the measurements obtained with the second tree shown in Fig. 4 (red). 



Fig. 6. Measured monoterpenoid emission rates $\left(\mu \mathrm{g} \mathrm{m}^{-2} \mathrm{~h}^{-1}\right)$ as a function of PPFD ( $\mu \mathrm{mol} \mathrm{m} \mathrm{m}^{-2} \mathrm{~s}^{-1}$ ) on (a) August 24-26, (b) September 5-6 and (c) September 30October 1, and comparison with different algorithms: G97 or G06 (in blue), S97 (in green), and the adjustable algorithm G06a (in red). The values of the fitted parameters n, $\alpha_{3}$ and $\alpha_{4}$ (see Eqs. (12)-(14)) are indicated for each period.

the maximal difference between morning and afternoon emissions is found to be much larger than the statistical error on the emissions. A similar behaviour was also observed for the first tree, for which the emissions were measured in July 2007 (data not shown). The hysteresis phenomenon was previously reported in the literature but has not been accounted for in existing BVOC emission algorithms. Dindorf et al. (2005) reported a significant delay in monoterpene emission from a $F$. sylvatica $L$. tree in the early morning, which could be better reproduced by the algorithm of Schuh et al. (1997) (S97, Eq. (6)) than by the the G97 algorithm. However, S97 was found to underestimate emission rates in the early evening in their study. The hysteretic behaviour has been described for other monoterpene emitting broadleaf tree species as well, e.g. the evergreen Q. ilex (Ciccioli et al., 1997).

The hysteresis might reflect the existence of monoterpenoid storage pools (Noe et al., 2010) and/or an acclimation to environmental conditions. In any case, it suggests a dependence of the emission rates on past PPFD levels. The S97 algorithm clearly failed to reproduce the diurnal cycle observed in this study, with large underestimations found at low PPFD levels (Fig. 6a). Although the MEGAN model includes a dependence on PPFD history, it also failed to reproduce the observed hysteresis (Fig. 6a). This was due to the choice of the averaging periods in G06, the past PPFD averages $P_{10 \mathrm{~d}}$ and $P_{24}$ h being initially constant in our experimental set-up.

The observed diurnal cycle of emissions can be reproduced only when assuming a dependence of the emissions on past PPFD fluxes averaged over a shorter period ( $n=10-13 \mathrm{~h}$, see Fig. 6 ). The averaging period $n$ and the parameters $\alpha_{3}$ and $\alpha_{4}$ of the adjustable algorithm, G06a, have been obtained by minimizing the root mean squared deviation between modeled and measured emission rates. The values obtained for $\alpha_{4}(0.0025-0.0038)$ are 5-8 times larger than in MEGAN, reflecting the significance of the PPFD history effect suggested by the measurements. The values for $\alpha_{3}$ (1.9 at the start of the experimental period, 5-10 at later stages) are also larger than in MEGAN $\left(\alpha_{3}=1\right)$, indicating that emission saturation occurs at lower PPFD values compared to MEGAN, as clearly seen on Fig. $6 \mathrm{~b}-\mathrm{c}$. The increase of $\alpha_{3}$ during the course of the experimental period is presumably related to senescence and acclimation to low light levels and the associated decrease in emission capacity, as discussed in the previous subsection.

\section{Conclusion}

The response of monoterpenoid emissions of two young F. sylvatica L. trees to changes in light intensity and temperature has been investigated in controlled growth chamber conditions. The observations show a clear dependence of the emissions on the past light and temperature levels experienced by the trees. In addition, a strong decline of the emission capacity was observed in late August and September, with an e-folding time of 18 days, most probably related to leaf senescence.

The response of the monoterpenoid emission capacities to temperature variations at a constant daily PPFD pattern could be fairly well described by a modified version of the MEGAN algorithm (Guenther et al., 2006) originally developed for isoprene emissions. The results of our study suggest a much stronger dependence of the emission rates on the past temperature conditions than in previous algorithms (Guenther et al., 2006; Gray et al., 2006), and a typical dependence on the average temperature of the past five days.

The observed diurnal cycle of the emissions confirms the hysteretic behaviour which has been previously described, with lower emissions in the morning than in the afternoon at the same PPFD values. This effect can be parameterized with a modified version of the MEGAN algorithm, through a dependence of the emissions to the average PPFD over the past 10-13 h. In addition, emission saturation is observed to occur at lower PPFD values compared to MEGAN.

Since the experiments were performed on young trees and at PPFD levels which are typical for shaded conditions, additional enclosure measurements in natural outdoor conditions are required to confirm the strong dependence on past temperature and light observed in this study, and to further refine the adapted version of the MEGAN algorithm developed from our measurements. In particular, the seasonal evolution of the model parameters in response to phenological development will require further investigation. Finally, the applicability of the modified MEGAN algorithm 
to BVOC emissions by other plant species will clearly require a more systematic investigation on the environmental dependence of these emissions.

\section{Acknowledgements}

The authors would like to thank the Belgian Science Policy Office (BELSPO) (contract number SD/TE/03A) for funding the IMPECVOC (Impact of Phenology and Environmental Conditions on BVOC Emissions from Forest Ecosystems) research project. Support from the Research Foundation - Flanders (FWO) (contract numbers $\mathrm{B} / 07659 / 02$ and $\mathrm{G} / 0031 / 07$ ) is also gratefully acknowledged. We also wish to thank Philip Deman, technician of the Laboratory of Plant Ecology, and the technical personnel of the Belgian Institute for Space Aeronomy for their outstanding support.

\section{References}

Arneth, A., Monson, R.K., Schurgers, G., Niinemets, U., Palmer, P.I., 2008. Why are estimates of global terrestrial isoprene emissions so similar (and why is this not so for monoterpenes)? Atmospheric Chemistry and Physics 8, 4605-4620.

Blake, R.S., Monks, P.S., Ellis, A.M., 2009. Proton-Transfer reaction mass spectrometry. Chemical Reviews 109, 861-896.

Ciccioli, P., et al., 1997. Use of the isoprene algorithm for predicting the monoterpene emission from the Mediterranean holm oak Quercus ilex L.: performance and limits of this approach. Journal of Geophysical Research 102, 23319-23328.

Copolovici, L.O., Filella, I., Llusià, J., Niinemets, U., Peñuelas, J., 2005. The capacity for thermal protection of photosynthetic electron transport varies for different monoterpenes in Quercus ilex. Plant Physiology 139, 485-496.

de Gouw, J., Warneke, C., 2007. Measurements of volatile organic compounds in the earth's atmosphere using proton-transfer-reaction mass spectrometry. Mass Spectrometry Reviews 26, 223-257.

Dindorf, T., et al., 2005. Emission of monoterpenes from European beech (Fagus sylvatica $\mathrm{L}$.) as a function of light and tempearture. Biogeosciences Discussions 2, 137-182.

Dindorf, T., et al., 2006. Significant light and temperature dependent monoterpene emissions from European beech (Fagus sylvatica L.) and their potential impact on the European volatile organic compound budget. Journal of Geophysical Research 111, D16305. doi:10.1029/2005JD006751.

Gray, D.W., Lerdau, M.T., Goldstein, A.H., 2003. Influences of temperature history, water stress, and needle age on methylbutenol emissions. Ecology 84, 765-776.

Gray, D.W., Goldstein, A.H., Lerdau, M.T., 2006. Thermal history regulates methylbutenol basal emission rate in Pinus ponderosa. Plant Cell and Environment 29, 1298-1308.

Guenther, A., et al., 1995. A global model of natural volatile organic compound emissions. Journal of Geophysical Research 100, 8873-8892.

Guenther, A., et al., 1999. Isoprene emission estimates and uncertainties for the Central African EXPRESSO study domain. Journal of Geophysical Research 104, 30625-30639.

Guenther, A., et al., 2006. Estimates of global terrestrial isoprene emissions using MEGAN (Model of Emissions of Gases and Aerosols from Nature). Atmospheric Chemistry and Physics 6, 3181-3210.

Guenther, A., 1997. Seasonal and spatial variations in natural volatile organic compound emissions. Ecological Applications 7, 34-45.

Hallquist, M., et al., 2009. The formation, properties and impact of secondary organic aerosol: current and emerging issues. Atmospheric Chemistry and Physics 9, 5155-5236.
Holzke, C., Dindorf, T., Kesselmeier, J., Kuhn, U., Koppmann, R., 2006. Terpene emissions from European beech (Fagus sylvatica L.): pattern and emission behaviour over two vegetation periods. Journal of Atmospheric Chemistry 55 81-102.

Joó, É., et al., 2010. Quantification of interferences in PTR-MS measurements of monoterpene emissions from Fagus sylvatica L. using simultaneous TD-GC-MS measurements. International Journal of Mass Spectrometry 291, 90-95.

Kahl, J., Hoffmann, T., Klockow, D., 1999. Differentiation between de novo synthesized and constitutively released terpenoids from Fagus sylvatica. Phytochemistry $51,383-388$.

Karl, M., Guenther, A., Köble, R., Leip, A., Seufert, G., 2009. A new European plantspecific emission inventory of biogenic volatile organic compounds for use in atmospheric transport models. Biogeosciences 6, 1059-1087.

Kesselmeier, J., Staudt, M., 1999. Biogenic volatile organic compounds (VOC): an overview on emission, physiology and ecology. Journal of Atmospheric Chemistry 33, 23-88.

König, G., et al., 1995. Relative contribution of oxygenated hydrocarbons to the total biogenic VOC emissions of selected mid-European agricultural and natura plant species. Atmospheric Environment 29, 861-874.

Kulmala, M., et al., 2004. A new feedback mechanism linking forests, aerosols, and climate. Atmospheric Chemistry and Physics 4, 557-562.

Monson, R.K., et al., 1994. Environmental and developmental controls over the seasonal pattern of isoprene emission from aspen leaves. Oecologia 99, 260-270.

Moukhtar, S., Bessagnet, B., Rouil, L., Simon, V., 2005. Monoterpene emissions from Beech (Fagus sylvatica) in a French forest and impact on secondary pollutants formation at regional scale. Atmospheric Environment 39, 3535-3547.

Noe, S.M., Ciccioli, P., Brancaleoni, E., Loreto, F., Niinemets, Ü, 2006. Emissions of monoterpenes linalool and ocimene respond differently to environmental changes due to differences in physico-chemical characteristics. Atmospheric Environment 40, 4649-4662.

Noe, S.M., Niinemets, Ü., Schnitzler, J.-P., 2010. Modeling the temporal dynamics of monoterpene emission by isotopic labeling in Quercus ilex leaves. Atmospheric Environment 44, 392-399.

Pétron, G., Harley, P., Greenberg, J., Guenther, A., 2001. Seasonal temperature variations influence isoprene emission. Geophysical Research Letters 28 1707-1710.

Rapparini, F., Baraldi, R., Miglietta, F., Loreto, F., 2004. Isoprenoid emission in trees of Quercus pubescens and Quercus ilex with lifetime exposure to naturally high CO2 environment. Plant, Cell and Environment 27, 381-391.

Schnitzler, J.-P., Lehning, A., Steinbrecher, R., 1997. Seasonal pattern of isoprene synthase activity in Quercus robur leaves and its impact on modeling of isoprene emission rates. Botanica Acta 110, 240-243.

Schuh, G., et al., 1997. Emissions of volatile organic compounds from sunflower and beech: dependence on temperature and light intensity. Journal of Atmospheric Chemistry 27, 291-318.

Schurgers, G., Hickler, T., Miller, P.A., Arneth, A., 2009. European emissions of isoprene and monoterpenes from the Last Glacial Maximum to present. Biogeosciences 6, 2779-2797.

Seinfeld, J.H., Pandis, S., 1998. Atmospheric Chemistry and Physics - From Air Pollution to Climate Change. John Wiley and Sons, New York, 1326 pp.

Sharkey, T.D., Singsaas, E.L., Lerdau, M.T., Geron, C.D., 1999. Weather effects on isoprene emission capacity and applications in emissions algorithms. Ecological Applications 9, 1132-1137.

Sharkey, T.D., Wiberley, A.E., Donohue, A.R., 2008. Isoprene emission from plants: why and how. Annals of Botany 101, 5-18.

Spirig, C., et al., 2005. Eddy covariance flux measurements of biogenic VOCs during ECHO 2003 using proton transfer reaction mass spectrometry. Atmospheric Chemistry and Physics 5, 465-481.

Staudt, M., Seufert, G., 1995. Light-dependent emission of monoterpenes by Holm Oak (Quercus ilex L.). Naturwissenschaften 82, 89-92.

Staudt, M., Joffre, R., Rambal, S., 2003. How growth conditions affect the capacity of Quercus ilex leaves to emit monoterpenes. New Phytologist 158, 61-73. 